\title{
Mejorar los conflictos: derechos de la Amazonía en mundos cosmopolíticos
}

\section{Bettering Conflict: Rights of the Amazon in Cosmopolitical Worlds}

RESUMEN

En el 2018, la Corte Suprema de Colombia declaró a la Amazonía como sujeto de derechos. Esta decisión se basó en una sentencia que otorgó derechos legales al río Atrato. A diferencia de este caso, impulsado por las comunidades ribereñas, la concesión de derechos a la Amazonía obliga a las autoridades municipales y comunidades locales a asumir nuevas responsabilidades establecidas en un fallo mayormente conceptualizado sin su participación. En este texto, reflexiono sobre cómo el desarrollo de los derechos de la naturaleza en presencia de actores regionales "mejoraría" los conflictos socio-ambientales en la Amazonía. En vez de buscar eliminar los conflictos mediante una combinación de ley y orden, sugiero elaborar un proceso de justicia a través de una co-presencia cosmopolítica.

Palabras clave: derechos de la naturaleza, jueces del fin del mundo, mejorar los conflictos, Amazonía.
KRISTINA LYONS

Universidad de Pensilvania,

Filadelfia, Estados Unidos.

$\square$ krlyons@upenn.edu

(D) ORCID: 0000-0003-2832-9425

ज Google Scholar

\begin{abstract}
In 2018, the Supreme Court of Colombia declared the country's Amazon a subject of rights. This decision was based on an earlier sentence that granted legal rights to the Atrato River. Different from this case, that was propelled by the riverine communities, the granting of rights to the Amazon
\end{abstract}


obliged municipal authorities and local communities to assume new responsibilities established in a ruling that was primarily conceptualized without their participation. In this article, I reflect on how the development of rights of nature in the presence of regional actors would "better" the socio-environmental conflicts affecting the Amazon Basin. Instead of seeking to eliminate these conflicts through a combination of law and order, I suggest that a process of justice could be elaborated through cosmopolitical co-presence.

Keywords: rights of nature, judges of the end of the world, bettering conflict, Amazon.

a idea jurídica de que la naturaleza posee derechos inalienables, similares a los derechos humanos, ha pasado de ser un concepto mayormente filosófico para constituirse en un fundamento de cambios en las políticas públicas de diferentes países en las últimas dos décadas. Ecuador capturó la atención de la prensa internacional al incluir un marco de derechos de la naturaleza en su Constitución del año 2008. Estos célebres cambios legislativos se basaron en trabajos anteriores del Community Environmental Legal Defense Fund (CEDLF), una fundación que apoyó a los ciudadanos del municipio de Tamaqua en Pensilvania, Estados Unidos, en la redacción de la primera ordenanza que se dio en el mundo sobre derechos locales de la naturaleza, en el año 2006.

Académicos llevan años escribiendo sobre los derechos de la naturaleza, pero las redes globales para desarrollar y promover la jurisprudencia de la Tierra, o una filosofía y práctica legal que reconoce los derechos y el valor inherente de la naturaleza -además de la interconexión de los sistemas vivos del planeta-, comenzaron a formarse en la década de los ochenta. Los movimientos indígenas, en el Sur global, impulsaron inicialmente dichos principios y agendas ${ }^{1}$. Identificando los límites del derecho ambiental, que tradicionalmente ha sido un régimen de permisos y licencias para regular la administración de los recursos naturales, los derechos de la naturaleza y los marcos de jurisprudencia de la Tierra pretenden centrarse en las diversas relaciones que las comunidades tienen con y en 
sus territorios - relaciones que la ley antes no era capaz de ver o reconocer- (Gómez-Rey et al., 2019).

En este artículo, presento una reflexión sobre los retos en juego en la emergente jurisprudencia climática, enfocándome en el caso STC-4360 que involucra a la Amazonía colombiana. Esta sentencia histórica, proferida por la Corte Suprema de Justicia en Bogotá en abril de 2018, reconoció a la Amazonía del país - un área que comprende alrededor del 35 \% del territorio nacional- como sujeto de derechos y con garantía de protección legal.

Sin desconocer la legitimidad y utilidad del activismo judicial en la transformación social y la fomentación de diálogos significativos entre el Estado y la sociedad civil con respecto a problemas estructurales y distributivos, planteo algunas preocupaciones sobre los impactos de una sentencia cuyo origen e implementación ha sido mayormente conceptualizado sin la participación de comunidades locales y autoridades regionales. En particular, los nuevos riesgos y formas de criminalización que pueden surgir cuando los mecanismos de conservación ambiental cambian (o no cambian) de manos de actores armados ilegales a fuerzas policiales y militares, además de las paradojas en que se enfrenta el piedemonte andino-amazónico, es decir, una encrucijada entre iniciativas de conservación y presiones extractivistas.

Reflexiono sobre cómo el reconocimiento de los derechos de la naturaleza, en presencia de actores regionales, podría "mejorar" los conflictos socio-ambientales en la Amazonía. En vez de buscar eliminar los conflictos mediante una combinación de ley y orden, sugiero elaborar un proceso de justicia a través de una co-presencia cosmopolítica que sitúa propuestas progresistas para desarrollar un judicial dialógico dentro del marco de las diversas particularidades de un territorio andino-amazónico.

\section{¿Quién cuida una "casa común"?}

El "Primer Foro Regional por los Derechos de la Amazonía: Nuestra Casa Común", tuvo lugar el 22 y 23 de noviembre de 2018 en el Centro Experimental Amazónico a las afueras de Mocoa, Putumayo. El evento se desarrolló en un quiosco inspirado en la arquitectura ancestral de las Malocas (casa comunal indígena amazónica), construido en medio de un lago artificial. A nuestro alrededor se podían observar variadas especies de fauna terrestre y acuática: un jaguar, un tigrillo, un yaguarandí, pecaríes (cerdos de monte), tucanes, anacondas y monos; todos ellos en corrales, áreas cercadas y estanques de agua. Estos animales habían sido 
rescatados de traficantes ilegales y estaban en una etapa de recuperación para finalmente ser devueltos a sus respectivos hábitats en la selva. Desde mi lugar en la audiencia miré hacia el escenario, donde se había convocado a líderes sociales indígenas, campesinos y afrodescendientes para compartir sus perspectivas sobre la Sentencia 4360, la cual reconoció a la Amazonía del país como sujeto de derechos.

El evento fue organizado por Corpoamazonia, una de las tres autoridades ambientales con jurisdicción sobre la Amazonía colombiana. Representantes de las comunidades rurales de la región habían sido invitados a intervenir, luego de varias presentaciones institucionales que explicaban los obstáculos estructurales que enfrenta Corpoamazonia en su capacidad de implementar las órdenes dictadas por la Corte. Un anciano indígena de Leticia, Amazonas, reveló abiertamente en su intervención que no sabía por qué lo habían invitado al evento. Se sentó con los brazos cruzados sobre el pecho, aparentemente poco impresionado por el ajetreo que se creaba alrededor del fallo. Hasta ese día, aquel hombre nunca había oído hablar de la sentencia, mucho menos de sus obligaciones jurídicamente vinculantes para las comunidades rurales de la región. Sus comentarios revelaron la problemática principal de las exclusiones perpetuadas por una sentencia judicial que fue dictada desde la capital del país con una mínima participación de comunidades locales y actores regionales.

Un aspecto preocupante de este fallo es que estas complicaciones van mucho más allá de una simple falta de difusión de información: mantienen una violencia histórica al interior de un país andino-céntrico que sigue tratando a la Amazonía como uno de sus territorios nacionales (en el mejor de los casos como una suerte de "periferia exótica"), históricamente administrado bajo la tutela de una oficina especial del gobierno central. Margarita Serje (2011) relata que estos "territorios salvajes", bajos en población, generalmente indígenas, y muy lejos de la capital y otros centros urbanos, primero se convirtieron en puestos de avanzada de misioneros, luego se establecieron como fronteras agrícolas y frentes de colonización crónicamente problemáticos para el Estado y, posteriormente, se conocieron como "zonas de orden público", con los epicentros de violencia más intensa del país a lo largo de más de cinco décadas de conflicto social y armado, y reducidos a la condición de una mera representación por parte de las élites polític ${ }^{2}$. El Estado sistemáticamente ha tratado a los habitantes de la región como objetos de intervención

Julio Quiñonez, en la novela En el corazón de la América virgen de 1924, presenta una caracterización de la región amazónica de principios del siglo XX a medio camino entre la ficción literaria y la etnografía. 
-en el sentido político más reduccionista, como un problema continuo por resolver- y no como protagonistas de sus realidades, con valiosos conocimientos ancestrales y populares con potencial de transformación y el derecho constitucional de participar en el ordenamiento territorial y las decisiones ambientales que afectan la gobernanza del territorio (Lyons, 2020).

Existe una gran desconfianza por parte de las comunidades locales hacia la institucionalidad, incluyendo a Corpoamazonia. Pequeños y medianos ganaderos de Puerto Guzmán, Putumayo, me contaron que han sido "bombardeados" con panfletos lanzados desde helicópteros militares que amenazaban con arrestar a cualquiera que sea descubierto talando árboles para expandir los potreros. Ellos están convencidos de que Corpoamazonia ha llevado "tigres" con dispositivos de rastreo GPS que, para que, en caso de ser cazados por la amenaza a su ganado, condujera a su arresto. Son conscientes que su propia ganadería ha producido la disminución del bosque y, por lo tanto, las fuentes de alimento de estos felinos. Se sienten atrapados en un círculo vicioso, ya que no reciben subsidios para la conservación de los bosques ni una asistencia técnica coherente para cambiarse a prácticas silvopastoriles. Al mismo tiempo, el Estado ha otorgado más concesiones a compañías petroleras y mineras multinacionales para intervenir en el territorio. Muestra de esos aumentos es que, en 2019, se adjudicaron 30 bloques petroleros en todo el país, en contraste con los 15 del lapso 2015-2018. En el piedemonte amazónico, en 2019, se ofertaron 8 bloques en los departamentos de Caquetá y Putumayo, justamente un año después del fallo judicial la sentencia 4360 (Díaz Parra, 2020).

Durante aquel foro, un funcionario enfatizó que Corpoamazonia tendría que depender del monitoreo y el control liderado por parte de las comunidades para combatir la deforestación. Habló sobre la necesidad de financiar la organización de comités ambientales a nivel de las juntas de acción comunal (JAC), la organización cívica, social y comunitaria central de las comunidades campesinas. Dijo esto justo antes de que un representante del sector minero-industrial hiciera una presentación sobre la imposibilidad de que los municipios se opongan legalmente a la explotación de las riquezas minerales del subsuelo. Explicó a la audiencia que un NO rotundo a la minería era algo irracional e inconveniente.

Los mensajes contradictorios del foro eran desconcertantes. Finalizando el evento, me encontré cada vez más preocupada por las paradojas y nuevos riesgos producidos por un caso legal que, principalmente, 
no fue impulsado por iniciativas de actores regionales o habitantes locales. Una serie de órdenes judiciales reconociendo los derechos de la naturaleza, dictadas desde la capital andina del país, obligaba a comunidades -ya históricamente marginalizadas- a asumir nuevas responsabilidades, al mismo tiempo que las industrias extractivas intensificaban su presencia en el territorio debido a las mismas dinámicas de desplazamiento y apropiación impulsadas por décadas de guerra.

La sentencia legal que reconoció a la Amazonía colombiana como sujeto de derechos produjo "excesos" y horizontes aspiracionales. Por exceso, tomo inspiración en las ideas de la antropóloga Marisol de la Cadena para pensar en "los límites" de las visiones progresistas, en general, y de los paradigmas de los derechos de la naturaleza en la incipiente jurisprudencia climática, en particular (2015, p. 15). Dado que los excesos tienden a ser ignorados, de la Cadena sostiene que la ignorancia -tanto como negación o como incapacidad para saber- anula lo que se descuida, convirtiéndolo invisible o inexistente (Taguchi, 2017). Propone que este fenómeno es más que una violencia estructural, porque "es una violencia que ni siquiera es" (de la Cadena et al., 2018, p. 172). En otras palabras, es una violencia ontológica que bloquea lo excesivo al no permitirle ser. Según la propuesta de Cadena, lo que debe ser controlado es ese poder de decidir lo que es y hacer desaparecer aquello a lo cual el conocimiento moderno no puede acceder. Intentos de expandir el campo jurídico hacia el reconocimiento de nuevos derechos y sujetos no están inmunes a perpetuar esta clase de violencia.

Convencionalmente, las políticas públicas provenientes de Bogotá han intentado erradicar los conflictos en la región andino-amazónica a través de una combinación de "ley" y "orden" (es decir, la violencia de la seguridad). Me atrevo a sugerir que la elaboración de un caso de derechos de la naturaleza, en la presencia de los habitantes de la Amazonía, podría "mejorar" los conflictos socio-ambientales que afectan la región en vez de simplemente intentar contener y/o anular dichos conflictos (Stengers, 2005, p. 996). Para la filósofa feminista Isabelle Stengers, la posibilidad de mejorar la forma de vivir los conflictos tiene que ver con la necesidad de pensar más despacio, lo que ella describe en términos del "slowing down of reason". Se refiere a no asumir que estamos impregnados con la autoridad de saber el problema que necesita estar resuelto, es decir, de ser dueños de la razón, además, de buscar pacificar fricciones y diferencias profundas a través de "la tolerancia" y procesos de consenso mayoritario que terminan aplastando dichas diferencias o desacuerdos e ignorando una serie de actores involucrados en las situaciones en disputa. 
¿Cómo se logra escuchar o presenciar realidades y actores que ha estado negados? ¿Cómo se puede construir un diálogo sin buscar "estar en común acuerdo"? En lugar de atribuir al derecho con el dominio prescriptivo de resolver dichos conflictos, se podría construir algo como una justicia a través de un proceso de co-presencia cosmopolítica que se basa en una propuesta verdaderamente dialógica. Con esto no me refiero a los espacios de diálogo como suelen ser construidos en las etapas de socialización o seguimiento y monitoreo que normalmente acompañan cualquier proyecto e intervención en los territorios, es decir, una participación/consulta previa que termina siendo posterior a las verdaderas discusiones en donde se toman decisiones. Más bien me refiero a los procesos de diálogo y participación ciudadana constantes que deberían formar parte de la creación de todas las políticas públicas, ordenamiento territorial y gobernanza ambiental. Múltiples realidades están en juego en lo que se conoce singularmente como la cuenca del Amazonas. Una justicia cosmopolítica podría lograrse, al menos provisionalmente, con el involucramiento de más actores y realidades territoriales (humanos y más allá que lo humano - jaguares, vacas, matas de coca y espíritus ancestrales, para nombrar sólo algunos de los seres que habitan los territorios de la gran cuenca).

La idea de la justicia sigue siendo esquiva en Colombia. Las actividades de justicia transicional están dando lugar a procesos penales, comisiones de la verdad y posibles programas de reparación, luego de la firma de los acuerdos de paz en el 2016 entre el gobierno nacional y las Fuerzas Armadas Revolucionaras de Colombia - Ejército del Pueblo (FARC-EP). Sin embargo, siguen existiendo un sinnúmero de conflictos violentos e inquietantes en todo el país, especialmente en las regiones fronterizas. El proceso de la justicia transicional al entrelazarse con el giro hacia legislación biocéntrica, provoca una serie de preguntas: ¿Cuándo podríamos decir que se ha materializado la justicia y a favor de quién se ha logrado?, ¿a qué conceptos de justicia nos referimos cuando tratamos de reparar las relaciones socio-ecológicas y la protección de ecosistemas que han sido expuestos a una multiplicidad de daños?, ¿las décadas de guerra y las nuevas vulnerabilidades durante un periodo posacuerdo de paz han excluido la posibilidad de algo más allá que una paz precaria?, ¿cuáles son las variaciones de justicia entre comunidades interétnicas que comparten territorios e historias de violencia?

En este texto, primero atiendo a estas interrogantes y las pongo en conversación con otras inquietudes sobre el fondo, la implementación y la extensión de los derechos de la naturaleza. Contemplo lo que pasa con las órdenes contenidas en la Sentencia 4360 una vez que abandonan las 
cortes, además de los impactos que tienen sus decisiones en el Estado, la sociedad civil, los movimientos sociales regionales y la opinión pública. Abordo preguntas sobre los roles y deberes de las comunidades locales en la transformación de las relaciones territoriales y la aplicación de estrategias de mitigación del cambio climático. Concluyo ofreciendo algunos comentarios propositivos para el activismo judicial. Estas reflexiones están basadas en una propuesta de "mejorar" la forma de vivir los conflictos, lo cual comienza con diálogos cosmopolíticos que reconocen las complejas y múltiples realidades que influencian las dinámicas de deforestación y degradación ambiental, incluyendo los "excesos" que la política convencional sistemáticamente ha negado a través de acciones de exclusión y desconocimiento.

\section{La proliferación de nuevos derechos para la "naturaleza"}

"Un juez hoy en día debe ser vanguardista", me dice el magistrado Luis Armando Tolosa, con su marcado acento santandereano. "Los jueces normalmente juzgan sobre el pasado, no sobre el futuro. La ley sigue las decisiones sociales. ¿Cómo se puede mantener el poder de las decisiones tomadas por los jueces después de la elaboración de nuevos derechos? Necesitan tener dientes para ser materializados." Es mayo del año 2019 y estoy sentada en el despacho del juez Tolosa en la Corte Suprema de Justicia en Bogotá, poco más de un año después de que dictó la histórica sentencia que más tarde fue materia de discusión durante el foro organizado por Corpoamazonia. El juez juega con sus gafas por un momento. Es un hombre delgado con una cabellera negra que lo hace parecer más joven que la mayoría de los otros magistrados de la Corte. "Los problemas ambientales requieren pruebas técnicas. No pueden permanecer en abstracto", dice, refiriéndose a los vínculos establecidos entre el cambio climático y los derechos constitucionales a la salud humana actual y futura. El juez Tolosa consideró todo esto en las conclusiones de dicha sentencia.

La Sentencia 4360 fue dictada el 5 de abril de 2018 en respuesta a un caso liderado por el Centro de Estudios Jurídicos y Sociales con sede en Bogotá, Dejusticia. Este centro reunió a un grupo de veinticinco niños y jóvenes de todo el país, en un rango de edad entre los 7 y 25 años, para presentar una demanda contra el presidente de la República, el Ministerio de Ambiente y Desarrollo Sostenible, el Ministerio de Agricultura y Desarrollo Rural, la Unidad Administrativa Especial de Parques Nacionales Naturales, las Gobernaciones de Amazonas, Caquetá, Guanía, Guaviare, Putumayo y Vaupés, y los 40 municipios de la Amazonía colombiana. La demanda reclamaba que sus derechos a un ambiente saludable, vida, seguridad alimentaria, acceso al agua y salud estaban amenazados por 
la incapacidad del gobierno para controlar la deforestación. A pesar de las obligaciones nacionales e internacionales y los compromisos voluntarios hechos en las Cumbres del clima, el país lamentablemente seguía contribuyendo al cambio climático. Los demandantes argumentaron que el gobierno estaba obligado a reducir la deforestación mediante al menos tres compromisos: 1) el Acuerdo de París comprometió a Colombia a reducir las emisiones de gases de efecto invernadero; 2) una Declaración Conjunta de Colombia, Alemania, Noruega y el Reino Unido, obliga al gobierno a reducir la deforestación neta a cero en la Amazonía para el año 2020; y 3) la Ley Nacional 1753 (aprobada en el año 2015), requería que el gobierno redujera la tasa nacional de deforestación anual.

La Corte examinó la Constitución de 1991 y encontró que sus conceptos, junto con la jurisprudencia vigente, el derecho internacional y estudios académicos, justificaban un reconocimiento del ambiente sano como derecho fundamental. También determinó que el gobierno, de hecho, no había abordado eficazmente el problema de la deforestación a pesar de sus obligaciones. La Corte basó su análisis en el principio de solidaridad que existe en el artículo 1 de la Constitución. Este artículo se refiere a la garantía de un Estado social de derecho fundado en principios que promueven la solidaridad entre personas. Sin embargo, en el caso de la Amazonía, la Corte argumentó que era necesario considerar "al otro" en este proceso de solidaridad, es decir, los otros que también habitan el planeta: animales, plantas y futuras generaciones, las cuales merecen disfrutar de las mismas condiciones ambientales de las generaciones de hoy. Además, el Principio de Precaución la empoderó para poder limitar posibles acciones de las presentes generaciones por una obligación de "no hacer" daño y al contrario de cuidar y custodiar los recursos naturales y el mundo futuro humano ${ }^{3}$.

Basado en este análisis, ordenó al gobierno que desarrollara una serie de planes de acción dentro de los cinco meses posteriores a su decisión. Estos incluían un Pacto Intergeneracional para la Vida de la Amazonía Colombiana (PIVAC), y estrategias para reducir la deforestación neta a cero, combatir las emisiones de gases de efecto invernadero y actualizar los planes de ordenamiento territorial municipales en todos los departamentos amazónicos. Al declarar la Amazonía como sujeto de derechos, la Corte también buscó promover el campo emergente de los 
derechos bioculturales ${ }^{4}$. Dichos derechos están relacionados intrínsicamente con las costumbres ancestrales de las comunidades, su arraigo, su forma de percibir la vida, su respeto por la tierra y la reciprocidad con la naturaleza la cual les otorga el sustento para el diario vivir (Pérez et al., 2017). La inspiración surgió de los principios constitucionales filosóficos presentados en el primer caso de derechos de la naturaleza en Colombia (STC-622) cuando la Corte Constitucional reconoció al río Atrato, uno de los ríos más largos y caudalosos del país, como sujeto de derechos en noviembre de 2016 (MacPherson y Clavijo-Ospina, 2018) (Figura 1).

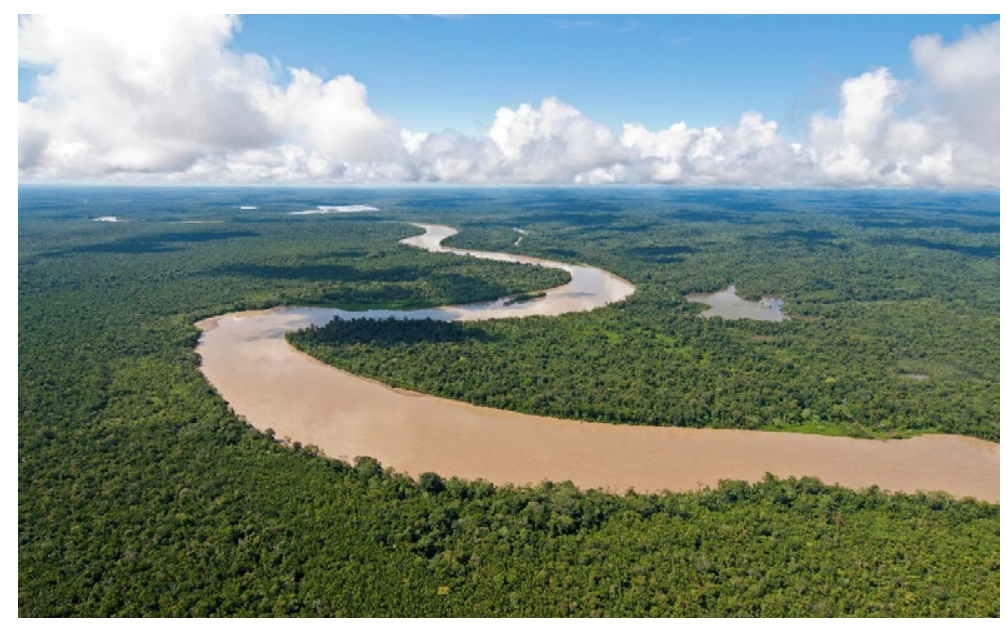

Figura 1. Vista aérea del río Atrato.

Fuente: Juan Manual Cardona Granda.

Tras la sentencia del Atrato, han proliferado una serie de casos de derechos de la naturaleza en el país. Diferentes ríos -La Plata, Coello, Combeima, Cocora, Cauca, Magdalena, Pance, Otún y Quindío- fueron reconocidos como entidades con derecho a la protección, conservación, mantenimiento, y restauración por parte del Estado. Un caso en el año 2017, reconoció que el emblemático oso de anteojos era sujeto de derechos, ampliando la legislación previa de protección animal que clasificaba a los animales como seres sintientes y garantizando su protección como parte de la biodiversidad ${ }^{6}$. Un año más tarde, un tribunal declaró como sujeto de derechos al páramo de Pisba luego de que políticas nacionales ordenaran

\footnotetext{
Para un resumen adicional de la Sentencia 4360, véase: https://www.escr-net.org/caselaw/2019/stc-43602018

5 Para más información acerca de la Sentencia 622 de 2016, consulte: https://www.corteconstitucional.gov. co/relatoria/2016/t-622-16.htm

6 Esta sentencia fue revisada posteriormente por la Corte Constitucional que mantiene la protección constitucional de los animales, pero no les reconoce el derecho al habeas corpus, manteniendo vigente el debate sobre si los animales son sujetos u objetos de derecho.
} 
la delimitación de estos ecosistemas para garantizar su protección contra la minería industrial entre otras actividades económicas, provocando controversias entre las comunidades locales ${ }^{7}$. Aún más reciente, los tribunales declararon sujetos de derechos a la Vía Parque Isla de Salamanca y el Parque Nacional Los Nevados, al ver los intentos fallidos por parte del Estado y su tecnocracia ambiental para proteger estos ecosistemas estratégicos de la actividad industrial, la agricultura, la deforestación y la degradación ambiental en general ${ }^{8}$.

Estos recientes giros legales biocéntricos han surgido tras las protecciones ambientales logradas en la Constitución de 1991 y en simultaneidad con las largas luchas de las comunidades étnicas y rurales en defensa de sus territorios, el derecho a la consulta previa y los derechos bioculturales ${ }^{9}$. También surgen en respuesta a las crecientes preocupaciones globales y nacionales sobre la fuerza antropogénica del cambio climático, la deforestación masiva y la pérdida de especies en medio del proceso actual de justicia transicional. En diversos contextos nacionales, temas como crímenes de guerra y violencia se han centrado principalmente en los seres humanos como víctimas y actores dentro de los marcos legales relacionados con la defensa y violación de los derechos humanos, como también, el derecho internacional humanitario. En Colombia existe un creciente debate público y legal sobre la manera en que los suelos, ríos, bosques y territorios, también son otras víctimas de la guerra que requieren procesos penales y reparaciones en el escenario de justicia transicional (CNMH, 2018; Lyons, 2017; Wilches Chaux, 2016).

Por ejemplo, la Ley de Víctimas de las Comunidades Indígenas de Colombia (Decreto-Ley 4633 de 2011) incorporó la noción de territorio como víctima, reconociéndolo como una "integridad viviente y sustento de identidad y armonía" que "sufre un daño cuando es violado o profanado por el conflicto armado interno" (artículo 11). En esta ley, la "sanación espiritual" se considera parte de la reparación integral del territorio

\footnotetext{
Véase: https://sostenibilidad.semana.com/medio-ambiente/articulo/la-naturaleza-colombiana-seriadeclarada-como-sujeto-de-derechos/45196 Al nivel regional, dos ex gobernadores, Camilo Romero (Nariño) y Carlos Amaya (Boyacá) firmaron un pacto político en 2019 reconociendo los derechos de la naturaleza en sus respectivos departamentos.

8 Véase: https://sostenibilidad.semana.com/actualidad/articulo/ecosistemas-sujeto-de-derecho-desnudanun-gran-vacio-en-gestion-ambiental/54727?fbclid=IwAR3lkzb9Qb0EIDh3Mm9cqz_4NugzRb2d6Rnqpq7Uu 2C4nkOaNzgdrRYDo5Q

Consulta previa refleja el derecho, definido por ley, de las comunidades indígenas y afrocolombianas a dialogar con el gobierno para asegurar su supervivencia colectiva y autonomía. Estas comunidades deben ser consultadas para aprobar leyes finales, proyectos y políticas que pueden afectarles directamente junto o sus territorios (Rodríguez, 2014).
} 
(artículo 8$)^{10}$. En otras palabras, este reconocimiento implica más derechos del territorio que derechos sobre el territorio (Izquierdo y Viaene, 2018; Ruiz Serna, 2017). En el 2019, la Unidad de Investigación y Acusación de la Jurisdicción Especial para la Paz (JEP) que es el tribunal establecido como parte de los mecanismos de justicia transicional, reconoció el medio ambiente como "víctima silenciosa" del conflicto armado". Recientes decisiones de la JEP han acreditado como víctimas al territorio Katsa Su del pueblo Awá y el territorio Eperara Euja del pueblo Eperara Siapidaara, además de los territorios de consejos comunitarios de Tumaco, Barbacoas y Ricaurte. Esta expansión de derechos y conceptos de victimización provocan interrogantes sobre lo que se entiende por la naturaleza y el territorio; quién habla en nombre de naturalezas particulares y quiénes actuarán o serán nombrados como guardianes de estas naturalezas y territorios, además de ser responsabilizados por su degradación, presente y futura restauración.

\section{Jueces del "fin del mundo"}

Sentado en su despacho, él bebiendo una taza de café y yo una de aromática, el juez Tolosa me guía con entusiasmo por los innovadores aspectos legales de la sentencia que dictó para la Amazonía. Comenta acerca de la contribución a la jurisprudencia sobre el cambio climático. La sentencia reconoce los derechos de las generaciones futuras, en particular su derecho a ser escuchados para la elaboración de políticas que les afectarán. También menciona el avance de los debates sobre los derechos de la naturaleza y la interpretación de los Acuerdos de París. En medio de nuestra conversación, hace referencia a un artículo de opinión, publicado en la Revista Semana de Colombia, que se titula provocativamente "Jueces del fin del mundo". El texto señala los retos orientados a futuro y las escalas planetarias en juego, en la emergente jurisprudencia climática (García Arbeláez, 2018). A pesar de su enfoque en gran medida esperanzador, el artículo pone de relieve, la lógica perversa de tal jurisprudencia. Un sistema jurídico heredado como consecuencia del colonialismo ha permitido un saqueo a gran escala y la degradación ambiental en nombre del crecimiento capitalista. Ahora las cortes están intentando hacer que los actores responsables rindan cuentas y respondan para reducir los fenómenos que ellos mismos produjeron. La débil capacidad institucional para aplicar las leyes existentes y los derechos recientemente establecidos,

10 Para más detalles sobre esta ley, véase el Decreto-Ley 4633 de 2011.

11 Ver JEP, Unidad de Investigación y Acusación de la JEP, «reconoce como victima silenciosa el medio ambiente,» Comunicado 009 (June 5, 2019), https:// www.jep.gov.co/SiteAssets/Paginas/UIA/sala-de-prensa/ Comunicado \%20UIA\%20- \%20009.pdf 
junto con la generalizada corrupción política, agravan los interrogantes más típicos que han surgido en los actuales debates sobre los derechos de la naturaleza.

Nuevos planteamientos ontológicos están surgiendo para el derecho occidental sobre el reconocimiento legal de seres vivos que antes se consideraban un conjunto de servicios ecosistémicos. Académicos y litigantes están estudiando el tema de la representación ahora que se ha concedido derechos a nuevas entidades y sujetos. Muchos se preguntan si el derecho penal y el derecho público proporcionan una protección más sólida o más efectiva que los nuevos movimientos basados en la ampliación de derechos. Las ideas recién concebidas sobre nuevas personalidades jurídicas son vulnerables a una rápida impugnación o revocación, teniendo en cuenta el hecho de que las empresas también tienen facultad jurídica como personas. Críticos han preguntado: ¿Es prudente o recomendable que el delta del río Níger pueda existir en afinidad legal con la petrolera Shell?, ¿dónde comienza y termina material y simbólicamente un bosque, en términos de su "ser"? (Macfarlane, 2019). Lecturas más optimistas de los derechos de la naturaleza afirman que los jueces y los sistemas jurídicos modernos en general, están creando nuevas herramientas para evidenciar las complejas y diversas relaciones que las comunidades étnicas, rurales y urbanas tienen con sus territorios. Sin embargo, a medida que comenzamos a discutir sobre las complejas realidades históricas, políticas y socioecológicas de la Amazonía del país, el juez Tolosa reconoce que "hay un problema en la construcción de la sentencia. Tiene las problemáticas locales escondidas en su interior."

Después de nuestra conversación, me quedé reflexionando sobre una serie de paradojas. No menos importante es la pregunta: ¿Qué es lo que se ignora o se niega cuando se afirma que los magistrados hoy en día están haciendo juicios en una era de crisis civilizacional que puede provocar "el fin del mundo"? Pensé en una visita que hice a un resguardo indígena del pueblo Nasa, en las afueras de la cabecera municipal de Puerto Guzmán, Putumayo. Las autoridades de la comunidad relataron sobre su llegada al territorio amazónico desde sus tierras ancestrales en los Andes, debido al latifundismo y el despojo provocado por la guerra. Mientras veía mucho potrero a nuestro alrededor, ellos explicaron que el Estado no proporciona suficiente asistencia técnica a las comunidades rurales basada en sistemas agroforestales amazónicos. Su experiencia no es diferente a la de muchas oleadas de campesinos que se establecieron en la región desde la década de 1930, producto de la colonización militar impulsada por la guerra Colombia-Perú (1932-1933), expulsados del interior del país durante los años de violencia bipartidista (1948-1958), 
o motivados por una prolongada historia de economías extractivas de auge y caídas, las más recientes girando en torno a cultivos ilícitos de coca, extracción de petróleo crudo y minería ilegal de oro (Ariza et al., 1998; CNMH, 2015).

Los pueblos indígenas, por supuesto, incluidos los pueblos nativos Andino-Amazónicos, entienden el presente como distópico. Abordan el cambio climático habiendo pasado ya por transformaciones irreparables de sus territorios y modos de vida inducidos por la violencia colonial y años de guerra (Whtye, 2018). Además, las aparentemente nuevas reformas constitucionales y epistemológicas que reconocen los derechos de la naturaleza surgen tras fenómenos mucho más antiguos. Se orientan desde las prácticas ancestrales, estructuras políticas y jurisprudencias de los pueblos indígenas que persisten a pesar de las estructuras hegemónicas del constitucionalismo liberal y las prácticas coloniales que continúan (Estupiñán Achury, 2019). La falta de reconocimiento de la contribución de estas jurisprudencias y filosofías de vida, no sólo en las discusiones académicas sino también en la creación e implementación de diferentes casos de derechos de la naturaleza, es uno de "los excesos" que las comunidades indígenas de la Amazonía señalaron en su análisis de la sentencia 4360.

Además, el piedemonte Andino-Amazónico y la llanura amazónica se encuentran en una compleja encrucijada política, económica y legal. Siendo un epicentro histórico del conflicto interno, social y armado, la zona occidental de la Amazonía está situada dentro de un estrecho vínculo geopolítico generado por la producción de cultivos ilícitos, el narcotráfico y las intervenciones de la guerra colombo-estadounidense contra las drogas. En contraste con la Amazonía oriental, que es más grande en términos de territorio y menos densamente habitada con una población indígena en gran parte dispersa, la región occidental se convirtió en una zona de asentamiento de personas desplazadas y marginalizadas del interior del país. Estas ocupaciones territoriales se establecieron sobre violentas reparticiones coloniales de tierras ancestrales indígenas, contribuyendo aún más, al empobrecimiento de las comunidades rurales, al fomento de actividades ilícitas y disputas territoriales duraderas entre actores armados que hasta la fecha no cesan a pesar de la firma del acuerdo de paz (Taussig, 1987; Ramírez, 2001). 


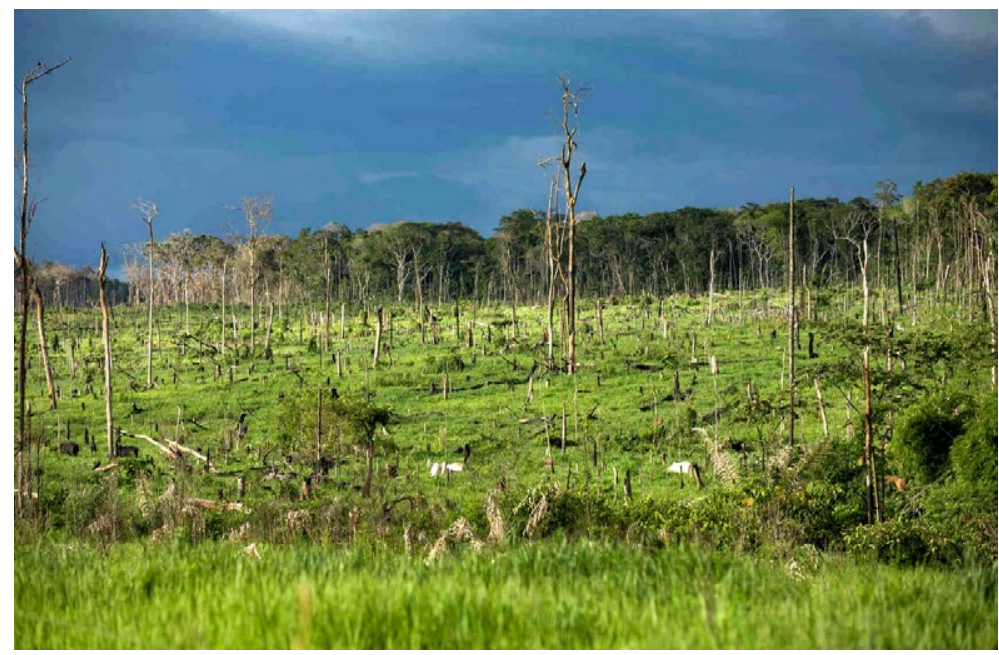

Figura 2. Impactos de la deforestación en el municipio de Puerto Guzmán, Putumayo.

Fuente: Kristina Lyons.

Puerto Guzmán (Putumayo), por ejemplo, es uno de los municipios más deforestados desde la firma del acuerdo de paz entre el gobierno y las FARC-EP (Figura 2). La relación de las FARC-EP con la conservación o degradación del ambiente ha sido compleja. Cesar Rodríguez, Diana Rodríguez y Helena Durán (2017), señalan que en algunos casos las condiciones materiales producidas por la guerra paradójicamente preservaron ecosistemas específicos, incluyendo la Amazonía, en comparación con los países vecinos que comparten la gran cuenca. En diferentes medidas, ciertas áreas se conservaron debido a la ausencia estatal, y, por ende, de iniciativas de infraestructura y desarrollo económico. De manera fluctuante y fragmentada, las FARC imponían mecanismos de conservación ambiental por razones tanto ideológicas como militares. En otros casos, estuvieron vinculados a actividades económicas ilícitas que fomentaban la degradación ambiental y la deforestación.

Desde la desmovilización oficial de las FARC, reconfiguraciones de actores armados -denominados como disidentes, mafias y bandas criminales de narcotráfico-, han llenado el vacío de poder que dejaron al retirarse de muchos territorios. Esto ha intensificado los conflictos socioambientales en la Amazonía occidental y otras regiones. En el año 2019, Colombia fue catalogado como el país más peligroso del mundo para los activistas ambientales ${ }^{12}$. De las 226 víctimas registradas por la ONG

Según la organización irlandesa defensora de derechos humanos, Front Line Defenders, más de 300 líderes de derechos humanos fueron asesinados en 31 países en el 2019, y casi la mitad de las víctimas fueran atacadas específicamente debido a su activismo ambiental. 108 de estas muertes fueron documentadas en Colombia (Tomassoni, 2020). 
Instituto de Estudios para el Desarrollo y la Paz (Indepaz), entre enero y noviembre de este mismo año, 113 de los asesinatos fueron cometidos en departamentos amazónicos y zonas de transición andino-amazónicas, estando el $80 \%$ de estos casos relacionados con disputas de tierras y recursos naturales ${ }^{13}$. Actualmente, la situación de Derechos Humanos en el país sigue siendo extremadamente preocupante.

El notable aumento de los delitos ambientales desde la firma de los acuerdos de paz, ha llevado al Estado a incrementar la militarización de la conservación a través de la creación de burbujas ambientales. Estas son parte de una estrategia nacional para ejercer un mayor monitoreo, prevención y control sobre la deforestación, la minería ilegal, como también el tráfico de fauna y flora mediante alianzas interinstitucionales reorganizadas entre las autoridades ambientales, la policía, el ejército y la fiscalía. A pesar de las medidas implementadas, las tasas de deforestación han ido en aumento. Según el Instituto de Hidrología, Meteorología y Estudios Ambientales (IDEAM), en los años 2015 y 2016, la deforestación en la región Amazónica aumentó un $44 \%$, pasando de 56.952 a 70.074 hectáreas perjudicadas (IDEAM, 2017). En el año 2018, una superficie boscosa equivalente a dos veces el tamaño de Bogotá fue arrasada $^{14}$. El boletín más reciente sobre Alertas Tempranas por Deforestación, publicado por el IDEAM en Bogotá, reveló que el 85\% de la deforestación ocurrida entre octubre y diciembre del año 2019 transcurrió en la Amazonía (Infoamazonía, 2020). Luego de ver las limitaciones del accionar de las burbujas, la consolidación de esta tendencia de "militarización verde" se dio después del operativo anti-deforestación en el Parque Nacional Natural Cordillera de los Picachos, en noviembre de 2018, que dio pie a la Campaña Artemisa, justo con el cambio de gobierno y después del dictado de la sentencia $4360^{15}$. El balance costo-beneficio de estas intervenciones en Parques Nacionales Naturales (PNN) como Picachos, Chiribiquete, La Macarena y La Paya, termina siendo desfavorable para el Estado. Algunas estimaciones señalan que un solo despliegue en el marco de la Operación Artemisa, tuvo un costo de 800 millones de pesos, dejando como balance

\footnotetext{
Véase: https://www.eltiempo.com/colombia/otras-ciudades/el-mapa-de-los-lideres-sociales-asesinadosen-colombia-184408

Véase: https://razonpublica.com/en-que-quedo-el-medio-ambiente-un-gran-dano-a-nuestros-bosques/

Agradezco a mi colega Carlos Olaya por haberme compartido información sobre la Campaña Artemisa a través de una comunicación personal el 11 de noviembre de 2020. Esta campaña se lanzó desde el municipio de la Macarena en Meta y se hizo notar como una gran ofensiva por la protección del patrimonio ambiental, estrategia que lideraron las Fuerzas Militares y la Policía Nacional, con el apoyo de la Fiscalía General de la Nación y el acompañamiento del Ministerio de Ambiente, Parques Nacionales Naturales y el Ideam, entre otras entidades. Véase: https://id.presidencia.gov.co/Paginas/prensa/2019/190428-puesta-marchaCampana-Artemisa-buscamos-parar-hemorragia-deforestadora-ha-visto-ultimos-anios-pais-Duque.aspx
} 
17 capturas de personas que en la mayoría de los casos fueron dejadas en libertad (Garzón Vergara et al., 2020).

Los pequeños y medianos taladores de bosque en la Amazonía están luchando con un panorama legal, económico y político, cambiante. Un talador ilegal de árboles asistió a un taller de educación ambiental que co-dirigí durante un evento de desarrollo sostenible en Mayoyoque, Puerto Guzmán. Era un hombre fornido de unos cincuenta años con rasgos curtidos y grandes manos callosas. Cuando se puso de pie y confesó a los demás participantes que taló 100 árboles en un solo día, las lágrimas brotaron de sus ojos. Preguntó frustradamente por qué el gobierno no apoyaba iniciativas económicas transitorias viables para ayudar a las familias rurales a conservar y reforestar la Amazonía, en lugar de colocar más retenes policiales y militares para detener a las personas involucradas en el tráfico ilegal de madera. Las tácticas militarizadas de conservación pueden convertirse en un modo de perpetuar la guerra por otros medios en tiempos oficiales de paz. Las estrategias de conservación represivas pueden continuar criminalizando a las comunidades rurales sin ofrecerles alternativas económicas viables que sean agroecológicamente apropiadas para la Amazonía y también involucran a una serie de entidades corruptas que otorgan licencias ilegales para el aprovechamiento forestal. Las burbujas ambientales no han establecido espacios permanentes de diálogo para garantizar la participación de la comunidad en la planeación territorial y las decisiones que dirigen las políticas públicas agrarias y ambientales. Los acuerdos de paz prometían una reforma agraria integral y cambios estructurales en la política antidrogas, pero la realidad está lejos del ideal en términos de los fracasos y limitaciones en la implementación de Programa Nacional Integral de Sustitución de Cultivos Ilícitos (PNIS) y los Programas de Desarrollo con Enfoque Territorial (PDET). Por otro lado, dicha militarización de los territorios tampoco ha brindado garantías y protección para líderes sociales, ambientales y excombatientes.

En el año 2016, anticipándose a la firma de los acuerdos de paz, el presidente de la empresa petrolera estatal Ecopetrol, fue citado en el periódico afirmando que "la paz nos va a permitir sacar más petróleo de las zonas vedadas por el conflicto. Con la paz esperaríamos tener la posibilidad de entrar a Caquetá mucho más fuerte, a Putumayo, a Catatumbo, sitios donde antes era difícil acceder" (El Espectador, 2016) ${ }^{16}$. Entre los años 2004 y 2018, el gobierno nacional firmó sesenta y siete contratos con diecinueve empresas para la exploración de reservas

\footnotetext{
Véase: https://www.elespectador.com/noticias/economia/la-paz-nos-va-a-permitir-sacar-mas-petroleo-dezonas-vedadas-por-el-conflicto/
} 
petrolíferas que la Agencia Nacional de Hidrocarburos (ANH) estima que existen en la cuenca Caguán-Putumayo ubicada en la Amazonía del país ${ }^{17}$. Además, la división regional creada por el Plan Nacional de Desarrollo 20142018 reclasificó la región históricamente designada como la Amazonía, en dos nuevas regiones: Centro-Sur y Región Llanos. Este cambio permitió modificaciones en el uso establecido de los suelos y por consiguiente en el tipo de proyectos de desarrollo y modelos económicos permitidos para entrar en el territorio (Díaz y Aguilar, 2018) (Figura 3).

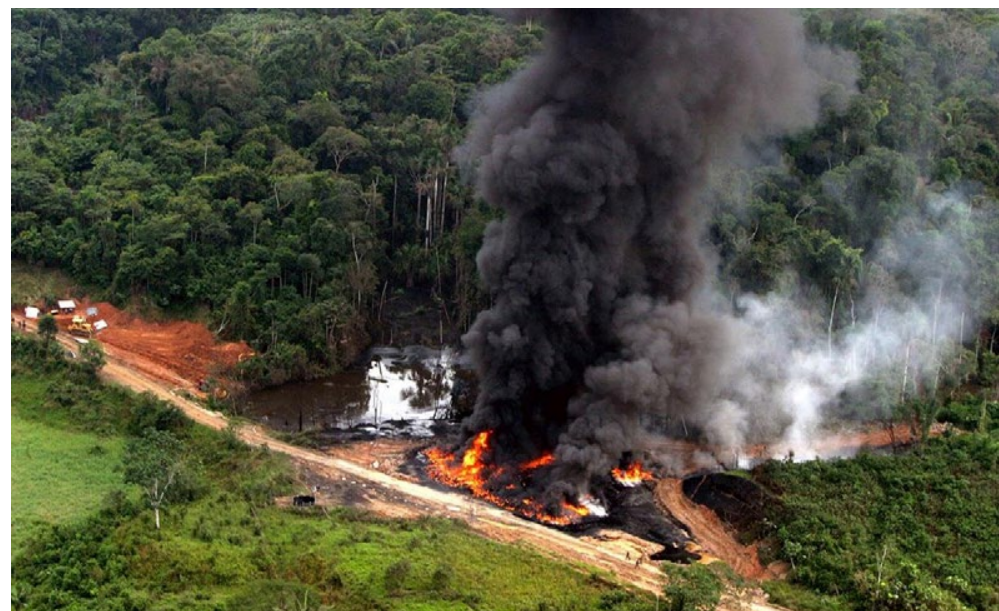

Figura 3. Daños ambientales provocados tras la voladura de un oleoducto por grupos armados.

Fuente: Archivo Semana.

Simultáneamente, desde la anterior administración de Santos y mantenida por la actual administración del presidente Duque con el apoyo de la Corte Constitucional, se ha bloqueado el derecho a organizar consultas populares. Según la Constitución, los municipios y, por lo tanto, los ciudadanos, tienen derecho a determinar el ordenamiento territorial y el uso de los suelos en sus municipios. Estos referéndums eran una manera de prohibir la minería industrial y los proyectos de hidrocarburos para proteger el patrimonio ecológico y cultural ${ }^{18}$. Los referéndums fueron una de las pocas herramientas democráticas disponibles para que

17 Véase: https://www.semana.com/contenidos-editoriales/hidrocarburos-son-el-futuro/articulo/ putumayo-clave-para-el-futuro-petrolero-del-pais/590016?fbclid=iwar1mlahuiln5vhlzo4bxm3jj 3d_rywlsqpmpqstyaz33kgizxulyewpdmeg

18 La sentencia SU-95/2018 dictada por la Corte Constitucional dio un golpe definitivo a la posibilidad de que las autoridades municipales y los ciudadanos organizaran consultas populares cuando definió que la consulta popular no es el mecanismo adecuado para dirimir las diferencias por el uso del subsuelo entre el Gobierno nacional, los municipios y sus habitantes. Con ello, se abrió un gran debate sobre los mecanismos idóneos de participación ciudadana y de coordinación y concurrencia para la toma de decisiones en materia de hidrocarburos y minería. 
las comunidades pudieran defenderse de las industrias extractivas y para garantizar la participación de las entidades territoriales, el principio de participación ciudadana en los planes de ordenamiento territorial y el carácter permanente del proceso de coordinación y concurrencia entre las prioridades de la nación y los planes de desarrollo regional y local de las entidades territoriales, incluyendo la participación ciudadana en el otorgamiento de concesiones para explorar y explotar minerales e hidrocarburos.

Desde el año 2014 ha habido continuos vaivenes legales entre sentencias judiciales que defienden y luego desconocen los derechos legales de los concejos municipales para firmar acuerdos con el fin de controlar, preservar y defender el patrimonio ecológico y cultural de sus territorios. Lamentablemente, también hubo demandas contra dichos acuerdos que prohibían proyectos extractivos y en algunos casos tribunales administrativos los declararon no válidos. Hay otros municipios, como es el ejemplo de la capital andino-amazónica del Putumayo, Mocoa, que se encuentra actualmente defendiendo su acuerdo que prohíbe la minería industrial de metales frente a demandas por parte de la Agencia Nacional Minera (ANM) y multinacionales mineras que buscan suspenderlo ${ }^{19}$. Como sostiene la ONG Asociación Ambiente y Sociedad, el mecanismo administrativo diseñado por la Agencia Nacional de Hidrocarburos (ANH) y ANM no tiene por objetivo hacer partícipes a los municipios en la toma de decisiones sobre la oferta de bloques, sino obligar la inclusión de la variable minero-energética en los POT, por medio de un mecanismo jerárquico, vertical y unilateral en el que los municipios no tienen posibilidades de incidir (Díaz Parra, 2020).

Maneras más insidiosas de imponer un modelo económico basado en la extracción se manifiestan a través de la sustracción institucional de áreas de reserva forestal. Se puede mencionar, como otro ejemplo, la realización de cambios en los documentos de planeación sobre el uso de los suelos sin seguir los procedimientos administrativos requeridos para realizar tales ajustes. También existe el hecho de que los sistemas de tenencia de la tierra impulsan la ganadería, convirtiendo estas áreas en potreros y cambiando sus posibles determinantes ambientales futuros para hacer que los proyectos extractivos e industriales sean permisibles. La errónea separación entre "suelo" y "subsuelo", que hace parte de las

\footnotetext{
40 municipios del país han expedido acuerdos municipales para prohibir diferentes actividades extractivas. Tribunales Administrativos declararon no válidos 15 acuerdos firmados en el departamento de Antioquia, 10 en el departamento de Huila y uno en Ibagué, Tolima por dar algunos ejemplos de las acciones de las cortes en obstaculizarlos. Agradezco a Rodrigo Negrete por brindarme esta información a través de una comunicación personal el 30 de septiembre de 2020.
} 
lógicas de la gestión de recursos naturales, desmantela la integralidad de este como un cuerpo natural. Más aún, ignora el hecho de que cualquier acceso a la riqueza del subsuelo debe pasar necesariamente por el suelo e involucra a sus ocupantes, guardianes y propietarios. Sin mencionar el falso dilema planteado por la Corte Constitucional, de acuerdo con el cual el subsuelo pertenece a la "nación", cuando realmente el suelo y el subsuelo son propiedad del Estado, que incluye, por supuesto, los entes territoriales y ciudadanos.

El Estado está otorgando concesiones a las multinacionales para el desarrollo de proyectos minero-energéticos, al mismo tiempo que criminaliza a las comunidades rurales para la deforestación. Esta es una profunda contradicción para las comunidades que habitan en la Amazonía y obstaculiza severamente los esfuerzos de conservación ambiental y la posibilidad de cumplir con las órdenes judiciales establecidas en la sentencia 4360. Desde las diversas perspectivas de las comunidades, ya sean cocaleras - cuyos sustentos de vida han sido envenenados por el glifosato durante los años de guerra contra las drogas-; pueblos indígenas que han vivido la desposesión de sus territorios ancestrales; o líderes sociales que enfrentan amenazas de muerte debido a su defensa de los bosques, fuentes de agua y biodiversidad regional de proyectos extractivos, "el fin del mundo" se parece más a un círculo vicioso constante que a una reciente amenaza remediable por una sentencia legal.

\section{Exclusiones y excesos frente pactos interculturales y pluralismo jurídico}

El 22 de agosto del año 2019, el Tribunal de Bogotá -encargado de vigilar el cumplimiento de la sentencia 4360-, declaró que: "ninguna de las entidades (gubernamentales) ha demostrado pleno cumplimiento a lo ordenado y que, por contera, lejos están de reducir a cero la deforestación en la Amazonía" (Infoamazonía, 2019). Las comunidades indígenas cuyos resguardos, según la Fundación Gaia, cubren 54.18\% de la extensión de la Amazonía del país, solicitaron por segunda vez al Estado que hiciera un llamado a un pacto intercultura ${ }^{20}$. Argumentaron que no solamente un pacto intergeneracional entre jóvenes y adultos debería ser construido, como está planteado actualmente en la Sentencia. Pidieron la inclusión de sus comunidades para lograr la incorporación de sus prácticas ancestrales e instrumentos de planeación ambiental y territorial propio, además de la jurisprudencia indígena y su capacidad de decisión como "autoridades públicas" que pueden garantizar el cuidado de la vida y la

20 Véase: "From Farms to Forests: Land Rights as an Impact", Gaia Amazonas, 2 de julio de 2019, disponible en https://www.gaiaamazonas.org/recursos/videos/60/ 
integridad cultural y territorial (Infoamazonía, 2019) ${ }^{21}$. El papel sustitutivo que los niños y jóvenes demandantes asumen para las generaciones futuras, dentro de la estructura de la sentencia, inadvertidamente les otorga un poder de representación para no sólo las comunidades indígenas amazónicas, sino para todos los habitantes rurales y urbanos de la región. La llamada por parte de las comunidades indígenas a este pacto intercultural es una forma de aceptar un exceso producido por la Sentencia 4360. Por aceptar, refiero a una forma de hacer visible o lo que de la Cadena describe en términos de "controlar la negación del exceso" (de la Cadena et al., 2018, p. 172). Se refiere a hacer visible lo que una violencia histórica y perpetua quiere negar: el protagonismo de las comunidades rurales como conocedores y guardianes ancestrales de las selvas de la región.

El carácter centralizado de la Sentencia 4360 se aparta notablemente del caso de los derechos de la naturaleza que involucró al río Atrato. Este caso fue impulsado por las preocupaciones de las comunidades ribereñas interétnicas, y la Sentencia dio lugar al establecimiento de una comisión de guardianes del río que actúan en su representación legal, en la planificación de su descontaminación y restauración ${ }^{22}$. Uno de los aspectos innovadores de la sentencia del río Atrato establece que el seguimiento de las órdenes puede ser interpretado y adecuado a los cambios sociales que se van presentando durante su implementación. Felipe Clavijo Ospina caracteriza este caso como una sentencia dialógica más que administrativa, en el sentido de que su eficacia es progresiva y cuenta con un mecanismo permanente de seguimiento para asegurar que lo ordenando se cumpla mediante el monitoreo comunitario por parte de la comisión de guardianes del río (Garzón, 2020). La adopción de una innovadora teoría de derechos bioculturales en el caso del río Atrato, basado en "la unidad profunda entre la naturaleza y la especie humana", permitió a la Corte reconocer la jurisdicción de comunidades indígenas y afrodescendientes como reguladores, guardianes, y tomadores de decisiones sobre el cuidado del río (Macpherson et al., 2020). Este es precisamente el contraste que señalaron las comunidades indígenas de la Amazonía entre un pacto intergeneracional y un pacto intercultural que reconocería estos derechos bioculturales y asignaría un cuerpo colectivo de guardianes para la defensa y recuperación del territorio.

21 La omisión de muchas comunidades indígenas de la Amazonía se produjo incluso cuando en la página 8 de la sentencia, se reconoce que seis autoridades indigenas (ACIMA, AIPEA, PANI, ACAIPA, ACIYA y ACIYAVA) han participado en la acción original de tutela presentada en la Corte. Véase: https://www.elespectador. com/noticias/medio-ambiente/indigenas-dicen-que-la-sentencia-que-otorga-derechos-la-amazonia-losdeja-por-fuera-articulo-893955,. Véase también, https://www.dejusticia.org/en/the-colombian-governmenthas-failed-to-fulfill-the-supreme-courts-landmark-order-to-protect-the-amazon/

22 Véase: https://www.corteconsitucional.gov.co/relatoria/2016/t-622-16.htm 
Las consecuencias de las exclusiones perpetuadas en la elaboración de la sentencia de la Amazonía se hicieron ver en cinco talleres regionales realizados en Florencia, Mocoa, San José de Guaviare y La Macarena, entre los meses de julio y agosto del 2018. A estas reuniones asistieron algunos de los jóvenes demandantes, representantes de diferentes organizaciones sociales y miembros de comunidades locales de la Amazonía. El propósito era difundir la sentencia y discutir la creación de dicho Pacto Intergeneracional. Los talleres se llevaron a cabo en las principales ciudades de la Amazonía, lo cual significó que las comunidades de las zonas rurales, que son el punto focal de los impactos de las órdenes judiciales, estuvieran subrepresentadas ${ }^{23}$. Además, para los habitantes locales, se repitieron los deficientes "mecanismos rápidos de consulta" que las empresas petroleras realizan a menudo para conseguir sus licencias de exploración y explotación. Una de las principales preocupaciones expresadas por los que asistieron fue el carácter sancionador de las repercusiones iniciales de la sentencia. A los habitantes locales les preocupaba que las intervenciones del estado para hacer cumplir su implementación, continuaran castigándolos en lugar de invertir en el bienestar social y ambiental del territorio. Destacaron que la conservación de los bosques y la reforestación no son actualmente opciones económicas viables como sustento de vida. Severos obstáculos les impiden obtener préstamos para financiar proyectos agroforestales. El sistema de crédito existente promueve la deforestación porque se concede préstamos casi exclusivamente para financiar proyectos de ganadería y agricultura industrial.

Durante los talleres también se plantearon interrogantes sobre la gobernanza local y el ordenamiento territorial. Muchos de los asistentes estaban indignados porque el gobierno nacional se había comprometido a lograr una meta de deforestación cero en la Amazonía, mientras continuaba otorgando licencias ambientales para el desarrollo de proyectos minero-energéticos en la misma región. El Estado parecía estar sumido en contradicciones cuando negaba la vocación forestal de los suelos de la Amazonía y al mismo tiempo asumía compromisos para salvaguardar estos mismos bosques. Debido a la falta de inclusión de sus visiones para el territorio, las comunidades indígenas, afrodescendientes y campesinas manifestaron temor de que el gobierno nacional continuara introduciendo proyectos "descontextualizados" que negativamente afectarían sus modos de vida. No menos importantes fueron sus preocupaciones sobre las violentas amenazas contra los líderes sociales que organizan a

3 Véase: https://www.dejusticia.org/en/the-colombian-government-has-failed-to-fulfill-the-supreme-courtslandmark-order-to-protect-the-amazon/ 
sus comunidades en defensa del territorio ${ }^{24}$. En el 2020, la revista Semana se refirió a esta racha de violencia como una "caravana de la muerte", que afligía a líderes comunitarios en el municipio de Puerto Guzmán, Putumayo, para nombrar sólo una de las zonas de la Amazonía afectada por el narcotráfico y sus disputas territoriales ${ }^{25}$.

Los habitantes también manifestaron su preocupación al no tener claridad sobre qué intereses están siendo representados y protegidos. $¿$ Deben las industrias extractivas, como usuarios del territorio, participar en el financiamiento de los mecanismos de ordenamiento ambiental y la delimitación de zonas de conservación? Además de ordenar la elaboración de un Pacto Intergeneracional, la Corte decretó a todos los municipios de la región actualizar sus planes de ordenamiento territorial dentro de los cinco meses posteriores a su decisión. Este mandato no respetó los plazos establecidos por ley para realizar el ordenamiento territorial. Tampoco contempló que la mayoría de los municipios de la región, que son de quinta y sexta categoría, no cuentan con estudios de gestión de riesgos, lo que en la actualidad es un requisito para la planificación territorial ${ }^{26}$.

Para el año 2017, sólo estaba actualizado el 25\% de los planes de ordenamiento territorial de la Amazonía, es decir, hay una notable carencia de información de línea base y capacidad de los organismos estatales para medir los costos ambientales de cualquier proyecto de infraestructura o extractivo (Díaz y Aguilar, 2018). Como señalan Cesar Rodríguez y Diana Rodríguez (2015), los tribunales, las sentencias y los mecanismos de seguimiento pueden estimular la formación de capacidades institucionales básicas para ocuparse de los problemas estructurales que provocan el surgimiento de los litigios mismos. Sin embargo, la forma de adquirir estas facultades en los municipios que carecen de infraestructuras, recursos y capacidad técnica, pueden provocar o perpetuar conflictos sectoriales y dependencias financieras de los grupos con capital económica con presencia regional como es el sector minero-energético.

24 Esta información se obtuvo a través de un intercambio de correo electrónicos con Dejusticia el 3 de agosto de 2019 y un documento interno presentado por Dejusticia al Ministerio de Medio Ambiente y Desarrollo Sostenible el 02 de agosto de 2018.

25 Véase: https://www.semana.com/nacion/articulo/la-caravana-de-la-muerte-los-misteriosos-asesinos-delideres-sociales-y-campesinos-en-el-putumayo/649382

26 Los municipios de quinta categoría tienen entre 10.001 y 20.000 habitantes e ingresos corrientes de libre destinación anuales que sean superiores a 15.000 y hasta veinticinco mil 25.000 salarios mínimos legales mensuales y los municipios de sexta categoría tienen una población igual o inferior a diez mil 10.000 habitantes y con ingresos corrientes de libre destinación anuales no superiores a quince mil 15.000 salarios mínimos legales mensuales; lo cual indica que son municipios con pocos recursos económicos disponibles para financiar cambios estructurales en su gobernanza ambiental. 
En el año 2018, Corpoamazonia firmó un acuerdo con la Agencia Nacional de Hidrocarburos y la Fundación Panamericana para el Desarrollo, con la finalidad de financiar la asistencia técnica necesaria para actualizar los planes de ordenamiento territorial y establecer determinantes ambientales, incluyendo las zonas de cobertura forestal que debían conservarse en 14 municipios de la Amazonía ${ }^{27}$. Dados los recursos de la industria petrolera, no es de extrañar que estuviera construyendo alianzas con una autoridad ambiental regional. Conservación Internacional Colombia, World Wildlife Fund y otras ONG ambientales que operan en la región, también financian aspectos de sus proyectos a través de acuerdos de cooperación con el sector petrolero. Estas controversias sobre intereses sectoriales en disputa se pueden intensificar cuando a las entidades gubernamentales no se les asignan fondos suficientes o personal técnico para apoyar el cumplimiento de nuevas responsabilidades legales. Ahora que estas entidades regulatorias y organizaciones no gubernamentales están involucradas en la implementación de los emergentes derechos de la naturaleza, existe la siguiente interrogante: ¿De qué manera pueden "mejorar" en vez de fomentar los conflictos entre intereses incompatibles y visiones divergentes para el ordenamiento territorial presente y el futuro de la región? (Figura 4).

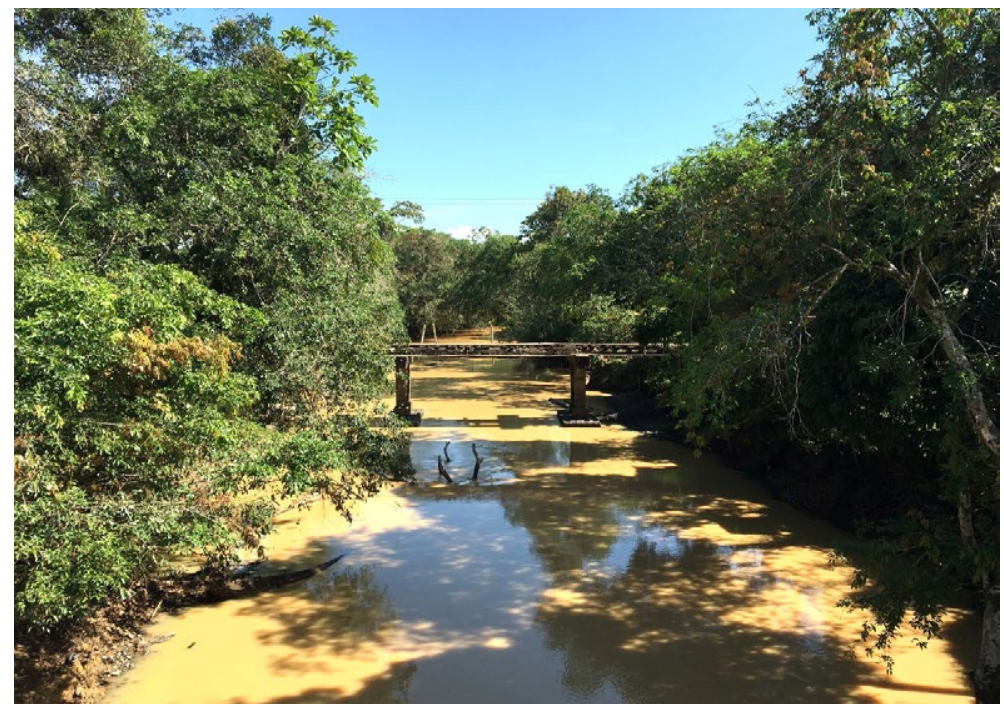

Figura 4. Afectación del río Mandur causada por la minería ilegal de oro en el municipio de Puerto Guzmán, Putumayo. Fuente: Kristina Lyons

Véase: http://www.corpoamazonia.gov.co/index.php/2-principal/1026-catorce-municipios-amazoniacuentan-con-determinantes-ambientales?fbclid=IwAR1rOBT-Oanra706pnb6SHFBHFUDqlp82Q5Abj1GX3Vi TyH6CG1OZIN1VtI 


\section{Reflexiones propositivas}

Cuando entrevisté al Magistrado Tolosa en su despacho en Bogotá, no interpreté su discurso de "innovación" y protecciones transgeneracionales como un deseo por su parte de conseguir algún estatus de notoriedad basado en el populismo. No hay duda de que la Sentencia 4360 es un fallo judicial importante en sus fundamentos filosóficosconstitucionales y como ejemplo de activismo judicial en la promoción de los derechos bioculturales, el reconocimiento de derechos de la naturaleza y la emergente jurisprudencia climática. Tiene potencial para actuar como una herramienta de protección contra la deforestación masiva y los proyectos extractivistas que están afectando a la Amazonía del país, e incluso, cuando los países vecinos como Brasil realizan una tala agresiva bajo la actual administración de Bolsonaro. El juez me explicó que la sentencia era una apuesta regional para inspirar a personas, jueces y gobiernos de otros países que comparten la gran cuenca del Amazonas a hacer demandas y tomar acciones legales similares.

También es importante reconocer la potencialidad del proceso de seguimiento de la sentencia que está realizando el Tribunal de Bogotá, además, de resaltar que este proceso es sui generis: ha citado 94 entidades en 12 audiencias para pedir rendición de cuentas y reorientar la ejecución de dicha decisión. Esto no se había visto antes, ni siquiera en los procesos de seguimiento de la Corte Constitucional ${ }^{28}$. En estas instancias de reorientación hay posibilidades de diálogo que abren un proceso de supervisión con el poder de estimular la discusión de alternativas políticas para resolver los problemas estructurales detectados en dicho fallo. Sin embargo, ¿cómo sería un proceso de justicia dialógica que desde su inicio intenta reconocer la diversidad ontológica que tendría que formar parte del origen de dicha sentencia además de los espacios de debate sobre su implementación?

Tolosa reveló que tenía poco conocimiento de las realidades históricas y contemporáneas de la región y sus habitantes, y de las complejas consecuencias que las órdenes de la Corte tendrían para las comunidades locales y las autoridades regionales. Parecería no haber considerado que el fallo podría criminalizar a los mismos sectores rurales que han sido estigmatizados, perseguidos y estructuralmente excluidos de las tomas de decisiones en el territorio. En muchos casos existe una enorme brecha entre los marcos normativos y las complejas realidades de

Agradezco a mi colega Carlos Olaya por haberme compartido información sobre el proceso de seguimiento de STC 4360 a través de una comunicación personal el 11 de noviembre de 2020 
los mundos por los que los jueces o abogados toman decisiones. El juez Tolosa me dijo que "una decisión judicial no puede resolver este tipo de problemas. Estos son asuntos para las políticas públicas". Este comentario, algo esquivo, establece una falsa división entre las esferas judiciales y políticas, donde la primera produce fallos legales que se canalizan a la segunda para la elaboración de políticas públicas, legislaciones y protocolos regulatorios con efectos públicos de gran alcance para el destino de miles de ciudadanos y la vida misma. El derecho es un producto de las realidades sociopolíticas, como mencionó el propio Tolosa. Son estas realidades concretas y plurales las que deberían informar la ley versus un mundo normativo que colapsa estas multiplicidades en el intento de "ordenar" los complejos mundos que coexisten, entran en fricción y defienden o destruyen lo que se conoce como la Amazonía. Estas realidades son las que deberían determinar el derecho y no al revés.

Mi intención no es criticar a este magistrado en particular o desconocer el replanteo del rol de los tribunales en las "sentencias estructurales" que han sucedido desde hace veinte años en el país, sino hacer observaciones propositivas respecto al imperativo de capacitar a jueces, fiscales, procuradores y abogados en el análisis histórico de los conflictos territoriales y socioambientales en las regiones específicas en donde se desempeñan o hacen sus intervenciones. Mis reflexiones propositivas intentan responder a las y los jueces que son conscientes de estae impartiendo órdenes muy complejas, que requieren de procesos delicados de seguimiento y concertación. Integral a este ejercicio sería la creación de equipos interdisciplinarios que puedan apoyarles en el análisis de dichos contextos para influenciar en las decisiones legales que se tomarán posteriormente, decisiones que a menudo exacerban en lugar de mejorar los conflictos entre diferentes grupos sociales y de tipo socioambiental en los territorios. Las decisiones de jueces distantes y los conceptos jurídicos ideados por abogados que no están situados en las realidades locales, corren el riesgo de volver a victimizar o ignorar a las poblaciones ya marginalizadas que tienen un acceso desigual a los mecanismos de justicia. Una decisión judicial sin conocimiento del territorio y sus realidades comunitarias, al menos a través de una inspección judicial o visita in situ, corre el riesgo de decidir "a ciegas" y sus resultados, en esas condiciones, son aún más inciertos.

Las reformas multiculturales de la Constitución de 1991 introdujeron derechos asimétricos y protecciones sociales diferenciados que aspiran a garantizar la integridad cultural de los grupos indígenas y afrodescendientes. Estas protecciones especiales no se han extendido a favor de las comunidades campesinas, a pesar de que comparten mundos rurales con 
experiencias similares de exclusión social e historias de violencia agraria (Duarte, 2016). La idea no es hacer encajar a los campesinos en el mismo molde de la legislación multicultural actual con sus promesas y deficiencias. Una pregunta más interesante sería: ¿Cómo reparar las relaciones fracturadas entre comunidades rurales que no son solo producto de las desigualdades sociales, políticas y económicas vinculadas a décadas de guerra, sino también a las premisas divisorias del constitucionalismo multicultural? Otras preguntas igualmente importantes son: ¿Cómo podemos imaginar e implementar prácticas de justicia más amplias, plurales y dialógicas?, ¿es posible respetar las particularidades de las relaciones originarias de los pueblos indígenas con sus territorios al mismo tiempo que se reconoce las realidades interétnicas y variaciones de justicia existentes?

Una reflexión necesaria con respecto a estas interrogantes debería comenzar con pensar en la protección de comunidades y territorios vulnerables en torno a una narrativa de derechos y no exclusivamente de sujetos (indígenas, afrodescendientes o campesinos) como ha sido planteada legal e históricamente. La ciudadanía tiene el derecho constitucional de participar en el ordenamiento territorial. El artículo 2 de la Constitución subraya la obligación del estado de facilitar la participación de todos los habitantes en las decisiones que los afectan y en la vida económica, política, administrativa y cultural de la nación.

Los métodos interétnicos e interculturales de ordenamiento territorial incorporan prácticas de justicia comunitaria, las cuales son más creativas, locales y pluralistas. Pueden trabajar juntos, aunque en fricción, con los marcos normativos de los tribunales ordinarios. En Colombia hay 102 grupos indígenas que históricamente han desarrollado sus propios principios para resolver problemas internos. A través de su Ley de Origen y la jurisprudencia indígena, estos grupos han fortalecido sus autoridades tradicionales, al mismo tiempo que recuperan sus formas de convivencia y autonomía (Rodríguez y González, 2019). Si bien, aún no han sido reconocidos oficialmente, los consejos comunitarios afrocolombianos en territorios colectivos también piden el reconocimiento de sus prácticas ancestrales de justicia negra (Izquierdo, 2019). La justicia comunitaria también forma parte de muchas organizaciones campesinas y agrarias.

¿Cuáles serían los impactos actuales de la Sentencia 4360 si efectivamente se hubiera establecido como un pacto intercultural que primero dialogaba ampliamente con las comunidades locales y las autoridades regionales?, ¿qué propuestas para mitigar la deforestación habrían surgido si las comunidades indígenas, ganaderos, representantes de las compañías petroleras, taladores y cocaleros hubieran sido invitados a una 
mesa de diálogo en la co-presencia de jaguares, bosques secundarios en recuperación, ganado, cultivos de coca y espíritus ancestrales?

Se podría caracterizar este tipo de escenario como un espacio de diálogo cosmopolítico que brinda la posibilidad de tejer alianzas inesperadas y de controlar la negación de excesos producida por la exclusión sistemática de actores y realidades locales. La idea no es que todos los actores regionales necesariamente estén (o quisieran estar) presentes en los espacios de debate o que los conflictos entre diferentes intereses sectoriales, visiones de desarrollo y propuestas de vida se queden resueltos o deban disolverse. La propuesta se concentra en ofrecer una alternativa a la combinación de ley y orden (ej. consejos de seguridad, retenes militares en las vías principales, operativos de burbujas ambientales y talleres de socialización), los cuales no han brindado garantías para las comunidades rurales, ni resultados en el control de la deforestación, y tampoco, espacios verdaderamente dialógicos donde se conversa con territorios, bosques y cuencas como seres vivos y relaciones vitales.

Reparar los daños a los bosques, las cuencas y sus guardianes espirituales, sería un punto de partida completamente diferente a lo que es enmarcar los problemas socioambientales en términos de crimen y castigo. Esto no significa que infractores no deban ser sancionados o que no se estén cometiendo delitos ambientales y violaciones de derechos humanos, como son el narcotráfico, acaparamiento de tierras públicas y minería ilegal. Sin embargo, como argumenta Rodrigo Botero (2020), las sanciones financieras no han detenido a los que tienen la capacidad económica para enfrentar un eventual caso de penalización. Tampoco se ha logrado afectar las finanzas de los grandes deforestadores ni capturar a un solo gran infractor en la Amazonía. Los habitantes locales están cansados de las tensiones en el accionar de la fuerza pública contra la población más vulnerable. Es necesario dar un paso atrás para volver a concebir los problemas socioecológicos $\mathrm{y}$, por ende, las soluciones a proponer, con la finalidad de evitar la replicación de exclusiones y estigmatizaciones históricas. Conceptos de daño y reparación pueden trascender los límites convencionales de la jurisdicción administrativa, las categorías de victimización y los enfoques seculares que refuerzan una división moderna entre «la naturaleza»y $\ll$ la cultura» ${ }^{29}$.

\footnotetext{
29 Las barreras para la introducción de un delito contra el medio ambiente en los tribunales nacionales e internacionales van desde cuestiones de culpabilidad y causalidad hasta resistencia política para ampliar la responsabilidad individual. Diferentes estudios sugieren que es más probable que se investigue y seleccione a casos en que el daño ambiental ocurrió en el contexto de los cuatro principales crímenes (genocidio, crímenes de lesa humanidad, crímenes de guerra y el crimen de agresión interestatal) que cuando no se ha producido en estos contextos (Killean, 2020).
} 
Ejemplo de lo anterior es la situación de ex cultivadores de coca de la vereda el Trébol en Puerto Guzmán, Putumayo. Algunos de ellos han reforestado de manera autónoma sus plantaciones de coca y calculan que una familia campesina necesitaría un subsidio de \$37,400 USD (141 millones de pesos colombianos) durante un período de diez años para restaurar, cultivar y proteger 15 hectáreas de bosque. A esto lo llaman la alternativa Mutumbajoy, que lleva el nombre de la familia campesina que comenzó hace once años este proyecto de silvicultura. Desde hace cuatro años la iniciativa de esta familia ha sido financiada a través de la Fundación ItarKa, ubicada en Puerto Guzmán, con el apoyo de pequeñas donaciones de ciudadanos franceses y alemanes.

Cuando visité por primera vez la finca Mutumbajoy en el año 2015, nos detuvimos para admirar un par de mariposas de color verde menta que estaban casi camufladas sobre un parche de liquen que habitaba la corteza de un árbol cercano. La familia me comentó que estas mariposas nunca aparecieron durante los casi quince años que se habían dedicado a convertir el bosque en un monocultivo de coca. La presencia de las mariposas fue una humilde señal de restauración ecológica, el retorno de la flora y fauna que acompaña a los procesos de reforestación y la recuperación de suelos y cuencas hidográficas (Lyons, 2018).

Las familias rurales del Trébol sostienen que, si los gobiernos de Estados Unidos y Colombia hubieran invertido sólo 7.5 millones de dólares de todo lo que gastaron en la erradicación forzosa de 2.3 millones de hectáreas de cultivos ilícitos durante 22 años, ahora habría 160.000 familias manejando de manera sostenible 2,6 millones de hectáreas de bosque amazónico en sistemas forestales y agroforestales ${ }^{30}$. Esta propuesta también implica resolver la informalidad de la tenencia de la tierra que afecta a tantas familias rurales en la Amazonía. Es una apuesta de reconciliación con el territorio liderada por los mismos habitantes que han participado en su degradación y deforestación, además de ser una propuesta política que descriminaliza a los habitantes para tratarlos como protagonistas capaces de transformar sus realidades y los problemas que afectan la región.

Los modos indígenas de jurisprudencia y filosofías de vida ya han mostrado tener comprensiones más amplias e integrales para abordar los daños territoriales. La llamada, por parte de los pueblos indígenas, a un

\footnotetext{
Esta información fue adquerida de un documento llamado "Alternativa Mutumbajoy a la Sustitución de Cultivos de Coca" que fue presentado por las comunidades rurales el 8 de mayo de 2017 en una reunión de difusión de los acuerdos de paz en Puerto Guzmán, Putumayo. Jorge Luis Guzmán me envió el documento por correo personal el 28 de junio de 2020 .
} 
pacto intercultural, implica acercarse al territorio, sentirlo y verlo como un ser vivo más allá de los conceptos ambientales basados en la biología moderna o una conglomeración de unidades de recursos naturales. Estas formas propias y ancestrales de conceptualizar la justicia se centran en atender a la ruptura y reparación potencial de relaciones - relaciones socioecológicas y relaciones no seculares. Abordar los daños a los territorios permite un imaginario colectivo de alternativas no carcelarias. Un enfoque de justicia restaurativa puede incorporar a actores distintos a los humanos en los marcos de daño, bienestar y reparación. La justicia transformadora también intenta abordar los conflictos entre las comunidades, individuos afectados y causantes de daño, además de los problemas sociales estructurales, como la pobreza, las acciones y negligencias del Estado y el papel de los actores armados ilegales que han conducido, permitido o intensificado los conflictos socioambientales y disputas territoriales.

La política puede terminar suprimiendo lo político, en el sentido de reducir los conflictos ontológicos necesarios, los vínculos apasionados y las diversas visiones del mundo y modos de vida (Ranciére, 1995). "Mejorar los conflictos" (Stengers, 2005) implica la creación de oportunidades para enfrentar y vivir los desacuerdos y divergencias de otro modo. Dichos desacuerdos pueden estar relacionados con la conceptualización misma de los problemas en cuestión, además del reconocimiento de las diversas realidades en juego cuando la Amazonía es deforestada y degradada. Esto implica ir más allá de la expectativa de simplemente resolver los conflictos, o de únicamente experimentarlos como disensos que deben ser controlados por la fuerza mediante estrategias represivas, como es la militarización de la conservación, y por otro lado, manejados por el otorgamiento de licencias para la explotación de recursos naturales.

De manera similar, los tribunales penales y ordinarios pueden participar inadvertidamente en la supresión de las variaciones de justicia que existen en cada territorio y entre los diferentes actores que contribuyen a los respectivos conflictos socioambientales. Como todas las leyes ambientales, los casos sobre los derechos de la naturaleza deben desafiar directamente el impulso implacable hacia la expansión económica y la explotación desenfrenada de las comunidades y los territorios. Es insuficiente intentar mitigar estos abusos permitiendo la extracción a nivel industrial mientras se criminaliza a los residentes locales y a pequeños y medianos productores (González, 2015). La proliferación de sentencias que reconocen derechos de la naturaleza no puede ocurrir a costa de excluir a los habitantes que nacen, viven, mueren y defienden los mismos territorios y ecosistemas que están siendo legalmente reconocidos 
y protegidos, o con su participación siendo únicamente una ocurrencia tardía en el proceso de seguimiento y monitoreo. La autonomía y la participación constante e informada de los entes territoriales y los ciudadanos en los proceses de planeación, ordenamiento territorial y la definición de los usos de los suelos es un derecho constitucional que debe ser protegido y promovido en todo momento, precisamente para evitar los niveles de destrucción ambiental y deforestación.

Las comunidades indígenas, junto con los movimientos afrocolombianos, LGTBI, ambientales, feministas, agrarios, de víctimas y pro-paz, han contribuido a la diversidad y extensión del pluralismo legal que ha impulsado los debates jurídicos contemporáneas sobre los derechos de la naturaleza entre la expansión de otros derechos. La idea no es solo llenar con mayor o mejor sustancia jurídica las sentencias que reconocen derechos a la naturaleza y lograr el cumplimiento "efectivo" de las órdenes judiciales. Es igualmente importante preguntarse si la extensión de nuevos derechos es lo que ciertos territorios, comunidades y sus diversos modos de vida quieren o necesitan.

En lugar de una reacción de celebración apresurada y universal frente a la proliferación de los derechos de la naturaleza, pido que también consideremos sus consecuencias no esperadas, complejidades éticas y alcances situados. Cada caso debe ser estudiado individualmente en sus orígenes, trayectoria, y esquemas de implementación dictados. Esto implica identificar la reproducción de ausencias y las realidades ignoradas que se convierten en los "excesos" en juego a medida que la legislación ambiental intenta afrontar sus limitaciones mediante un giro biocéntrico. También implica fomentar diálogos entre una compleja gama de actores regionales en donde los conflictos y desacuerdos sobre cómo abordar los problemas de la deforestación se pueden vivir de maneras más amplias que no asuman simplemente conocer los problemas que deben resolverse y la definición de actores legítimos y/o existentes que deberían estar presentes en dichas instancias de diálogo.

Comprometerse con las violentas realidades y legados coloniales de la deforestación masiva requieren enfoques creativos e inclusivos que no repliquen exclusiones históricas, sino que busquen "transformar las relaciones (de cada actor) con sus propios conocimientos, esperanzas, temores y recuerdos" (Stengers, 2005, p. 1002). Esta transformación también incluye las visiones legalistas que suponen conocer la división moral entre el bien y el mal, además de las categorías y jerarquías de victimización y las mejores maneras de incluir y proteger a otros tradicio- 
nalmente marginados, incluyendo a los bosques, matas de coca, ancestros, jaguares y mariposas.

Reunir a ganaderos, taladores, comunidades indígenas, afrodescendientes y campesinas, residentes urbanos, jóvenes y ancianos, autoridades ambientales y estatales regionales, trabajadores de ONG, abogados, jueces, movimientos sociales, cocaleros, mineros ilegales y ancestrales, representantes de empresas petroleras y mineras, fuerzas policiales y militares, y cualquier otro número de actores relevantes para la conversación, es sólo un primer paso. Sin embargo, definitivamente no debería ser un apéndice. Las comunidades locales, actores regionales y sus diversas realidades territoriales son el núcleo de tal Sentencia. No porque sean los únicos o incluso los principales motores de la deforestación y degradación ambiental, sino porque son sus vidas las que están directamente implicadas, así como sus saberes y su presencia territorial que garantizarán (o no) la implementación y éxito futuro de cualquier sentencia.

Las largas luchas de los habitantes de la Amazonía para crear alternativas a los modelos de desarrollo extractivistas, la política antidrogas militarizada y las condiciones actuales de violencia estructural existieron mucho antes de la influencia simbólica y las obligaciones jurídicamente vinculantes de un fallo judicial innovador. Parece más instructivo aprender lecciones de aquellos que no solo han sobrevivido, sino que continúan existiendo y floreciendo frente al "fin de sus mundos", en lugar de desconocer las raíces ancestrales y populares de los giros legales biocéntricos de nuestros tiempos.

\section{Referencias bibliográficas}

Ariza, E., Ramírez, M. C. y Vega, L. (1998). Atlas Cultural de la Amazonia Colombiana: La Construcción del Territorio en el Siglo XX. ICANH.

Botero, R. (5 de octubre de 2020). Señor Minambiente hablemos de deforestación en serio, Tierras y Medio Ambiente. https://cerosetenta.uniandes.edu.co/senor-minambientehablemos-de-deforestacion-en-serio/

Centro Nacional de Memoria Histórica (CNMH). (2018). Narrativas de la Guerra a través del Paisaje. CNMH.

Centro Nacional de Memoria Histórica (CNMH). (2015). Petróleo, Coca, Despojo Territorial y Organización Social en Putumayo. CNMH.

de la Cadena, M. (2015). Earth Beings: Ecologies of Practice Across Andean Worlds. Duke University Press. 
de la Cadena, M., Risør, H. y Feldman, J. (2018). Aperturas onto-epistémicas: conversaciones con Marisol de la Cadena. Antípoda. Revista de Antropología y Arqueología, 32, 159-177. https://doi.org/10.7440/antipoda32.2018.08

Díaz Parrra, K. (2020). Entre el Estado unitario y la autonomía territorial: Implementación de los principios de coordinación y concurrencia por parte del sector petrolero en el piedemonte amazónico. Asociación Ambiente y Sociedad.

Díaz Parra, K. y Aguilar Herrera, M. A. (2018). Ordenamiento territorial y ambiental de la Amazonía colombiana en el posconflicto. Asociación Ambiente y Sociedad.

Duarte, C. (2016). Desencuentros territoriales: Caracterización de los conflictos en las regiones de la altillanura, Putumayo y Montes de María. Instituto Colombiano Antropología e Historia.

Estupiñán Achury, L. (2019). Neconstitucionalismo ambiental y derechos de la Naturaleza en el marco del nuevo constitucionalismo latinoamericano, En L. Estupiñán Achury, C. Storini, R. Martínez Dalmau y F. A. de Carvalho Dantas (eds.), La Naturaleza como sujeto de derechos en el constitucionalismo democrático (pp. 365-387). Universidad Libre.

García Arbeláez, C. (26 de abril de 2018). Los jueces del fin del mundo. Semana Sostenible. https://sostenibilidad.semana.com/opinion/articulo/carolina-garcia-opinionsemana-sostenible-los-jueces-del-fin-del-mundo/40885

Garzón, C. A. (14 de febrero de 2020). Los derechos de la naturaleza se sintonizan con la conciencia ambiental de nuestro tiempo. La Silla Vacia. https://lasillavacia.com/ silla-academica/universidad-del-rosario/los-derechos-naturaleza-se-sintonizanconciencia-ambiental

Garzón Vergara, J. C., Riveros Gómez, A. y Tobo, P. A. (2020). Fuerzas Militares y la protección del ambiente: Roles, riesgos y oportunidades. FIPA. http://www.ideaspaz.org/ publications/posts/1894

Gómez-Rey, A., Vargas-Chaves, I. y Ibañez-Elan, A. (2019). El caso de la Naturaleza: derechos sobre la mesa. ¿Decálogo o herramienta? En L. Estupiñán Achury, C. Storini, R. Martínez Dalmau y F. A. de Carvalho Dantas (eds.) La Naturaleza como sujeto de derechos en el constitucionalismo democrático, editado (pp. 423-444). Universidad Libre.

González, C. (2015). Bridging the North-South Divide: International Environmental Law in the Anthropocene. Pace Environmental Law Review, 32, 407-433. https:// digitalcommons.pace.edu/pelr/vol32/iss $2 / 3$

IDEAM. (2017). Sistema de monitoreo de bosques y carbono para Colombia. IDEAM.

Infoamazonia. (2 diciembre de 2019). Indígenas dicen que la sentencia que otorga derechos a la Amazonia los deja por fuera. El Espectador. https://www.elespectador.com/ noticias/medio-ambiente/indigenas-dicen-que-la-sentencia-que-otorgaderechos-a-la-amazonia-los-deja-por-fuera/

Infoamazonía. (29 de abril de 2020). Se disparó la deforestación en la Amazonia colombiana (otra vez). El Espectador. https://www.elespectador.com/noticias/medioambiente/se-disparo-la-deforestacion-en-la-amazonia-colombiana-otra-vezarticulo-917069/ 
Izquierdo, B. y Viaene, L. (27 de junio de 2018). Decolonizing transitional justice from indigenous territories. Justicia en las Américas. https://dplfblog.com/2018/06/27/ decolonizing-transitional-justice-from-indigenous-territories/\#_ftn8

Izquierdo, G. (4 de septiembre de 2019). Justicia negra: sobrevivientes de un mundo que no se volverá a ver. Justiciarural. http://justiciarural.com/justicia-negra/?fbclid=IwAR3skeQm6OJwA8TSXE22GdzduSMbT0XoBBwQ57HOX-LKujwyEs3XGMq6OE

Kauffman, C. y Martin, P. (2016). Can Rights of Nature Make Development More Sustainable? Why Some Ecuadorian lawsuits Succeed and Others Fail. World Development, 92, 130-142. https://econpapers.repec.org/scripts/redir.pf?u=https\%3A\%2F\%2Fdoi. org\%2F10.1016\%252Fj.worlddev.2016.11.017;h=repec:eee:wdevel:v:92:y:2017:i:c:p:130-142

Killean, R. (2020). From ecocide to eco-sensitivity: 'greening' reparations at the International Criminal Court. The International Journal of Human Rights. https://doi.org/10.1080 /13642987.2020.1783531

Lyons, K, (2018). Chemical Warfare in Colombia, Evidentiary Ecologies, and Senti-actuando [Feeling-acting] Practices of Justice. Social Studies of Science 48(3), 414-437.

Lyons, K. (2020). Vital Decomposition: Soil Practitioners and Life Politics. Duke University Press.

Lyons, K. (25 de mayo de 2017). ¿Cómo sería una paz territorial?: Iniciativas de Justicia Socioecológica en el Sur. A la orilla del río. http://alaorilladelrio.com/2017/05/25/ como-seria-la-construccion-de-una-paz-territorial-iniciativas-de-justiciasocioecologica-en-el-sur/

Macfarlane, R. (2 de noviembre de 2019). Should this tree have the same rights as you? The Guardian. https://www.theguardian.com/books/2019/nov/02/trees-have-rightstoo-robert-macfarlane-on-the-new-laws-of-nature

Macpherson, E. y Clavijo Ospina, F. (2018). The Pluralism of River Rights in Aotearoa, New Zealand and Colombia. The Journal of Water Law 25(6), 283-293. https://doi. org/10.31235/osf.io/rdh4x

Macpherson, E., Ventura, J. T. y Clavijo Ospina, F. (2020). Constitutional Law, Ecosystems, and Indigenous Peoples in Colombia: Biocultural Rights and Legal Subjects. Transnational Environmental Law, 1-20. http://hdl.handle.net/20.500.12495/4587

Quiñones, J. (1948). En el Corazón de la América Virgen. Editorial ABC.

Ramírez, M. C. (2001). Entre el estado y la guerrilla: Identidad y ciudadanía en el movimiento de los campesinos cocaleros del Putumayo. ICANH.

Ranciére, J. (1995). On the Shores of Politics. Verso.

Rodríguez Garavito, C., Rodríguez Franco, D. o Durán Crane, H. (2017). La paz ambiental: Retos y propuestas para el posacuerdo. DeJusticia.

Rodríguez Garavito, C y Rodríguez Franco, D. (2015). Juicio a la exclusión: El impacto de los tribunales sobre los derechos sociales en el sur Global. DeJusticia, Siglo Veintiuno Editores.

Rodríguez, G. A. (2014). De la consulta previa al consentimiento libre, previo e informado a pueblos indígenas en Colombia. Ibáñez. 
Rodríguez, G. A., y González, N. C. (2019). La jurisdicción especial indígena y los retos del acceso a la justicia Ambiental. En L. Estupiñán Achury, C. Storini, R. Martínez Dalmau y F.A. de Carvalho Dantas (eds.), La Naturaleza como sujeto de derechos en el constitucionalismo democrático (pp. 473-494). Universidad Libre.

Pérez, C., Vargas, M., Estévez, X. y Aguilar-Barreto, A. J. (2017). Aplicabilidad del marco jurídico ambiental: caso barrio San Rafael De Cúcuta. En M. Graterol Rivas, M. Mendoza Bernal, R. Graterol Silva, J. Contreras Velásquez, J. Espinosa Castro (eds.), Derechos humanos desde una perspectiva socio-jurídica (pp. 85-102). Publicaciones Universidad del Zulia.

Ruiz Serna, D. (2017). El territorio como víctima: Ontología política y leyes de víctimas para comunidades indígenas y negras en Colombia. Revista Colombiana de Antropología 53(2), 85-113. https://doi.org/10.22380/2539472X.118

Serje, M. (2011). El Revés de la Nación: Territorios Salvajes, Fronteras y Tierras de Nadie. Universidad de los Andes.

Stengers, I. (2005). The Cosmopolitical Proposal. En B. Latour \& P. Webel (eds.), Making Things Public (pp. 994-1003). MIT Press.

Taguchi, Y. (16 de mayo de 2017). An Interview with Marisol de la Cadena. NatureCulture. https://www.natcult.net/interviews/an-interview-with-marisol-de-la-cadena/

Taussig, M. (1987). Shamanism, Colonialism and the Wild Man: A Study in Terror and Healing. Chicago University Press.

Tomassoni, T. (23 de febrero de 2020). Colombia was the deadliest place on Earth for environmental activists. It's gotten worse. NBC News. https://www.nbcnews. com/science/environment/colombia-was-deadliest-place-earth-environmentalactivists-it-s-gotten-n1139861

Whyte, K. (2018). Indigenous science (fiction) for the Anthropocene: Ancestral dystopias and fantasies of climate change crises. Environment and Planning E: Nature and Space 1(1-2), 224-242. https://doi.org/10.1177\%2F2514848618777621

Wilches Chaux, G. (2016). Base ambiental para la paz. La necesidad de hacerle gestión de riesgo al paz-conflicto. Oxfam. 